\title{
Influence of High Temperature Elastic-Plastic Small Crack Growth Behavior in a Nickel-Base Superalloy on the Life Prediction of Structural Components
}

\author{
A. H. Rosenberger ${ }^{+}$, E. Andrieu ${ }^{++}$, and H. Ghonem ${ }^{+}$ \\ ${ }^{+}$Mechanics of Solids Laboratory, Department of Mechanical Engineering \\ University of Rhode Island, Kingston, Rhode Island 02881 (USA) \\ ${ }^{+}$Centre des Materiaux, Ecole des Mines de Paris \\ B.P. 87 - 91003 Evry Cedex (France)
}

\begin{abstract}
The role of small crack behavior on life predictions is addressed with particular reference to cracks growing in the notch plastic zones of geometric stress concentrations. An experimental study of the elastic-plastic fatigue behavior of small surface cracks in Alloy 718 at $650^{\circ} \mathrm{C}$ was conducted under global strain control. During cycling, crack lengths were continuously measured using the direct current potential drop technique while the near field crack mouth opening displacement was measured using a laser interferometry technique. Crack tip plastic zones were measured by a post test metallographic technique. The anomalous growth behavior discovered at short crack lengths has been analyzed using several driving force parameters in an attempt to consolidate its growth rate with that of long cracks. This analysis has demonstrated that the anomalous growth rate is a transient phenomena and not an intrinsic feature of the material. The conclusion of this study is that in turbo-machinery, accurate residual life predictions for components of Alloy 718 can be based on the integration of long crack growth rate data for this alloy.
\end{abstract}




\section{Introduction}

During the past two decades, drastic changes have occurred in the design criteria of gas turbine engines. Previously, most engine components were designed based on creep and stress rupture properties of the materials. However, demands to improve the performance and efficiency of gas turbines has caused a transition in the life-limiting mechanism for over $75 \%$ of the rotating components in an engine to low cycle fatigue [1]. There are several approaches based on crack initiation and growth that have been used to integrate fatigue data into the design life calculations.

Realizing that most components contain material inhomogeneities or machining defects which act as cracks has lead to defect tolerant design approaches [2]. Here, component life is based on an integration of crack propagation rates from an initial crack length, based on nondestructive investigation (NDI) techniques, to a critical size for the component. An extension of this approach allows individual components to be returned to service following a NDI for cracks. In this "retirement for cause" approach, the variability of the crack initiation is exploited, extending the useful life of the component. The safe life is generally determined from an integration of crack growth rates from the reliable NDI limit. At or before these safe intervals, the components are inspected for cracks. If no cracks are detected, the component is returned to service until a subsequent inspection discovers a crack. At this time, the component is removed from service. The safety of this approach is critically dependant on the NDI technique and accurate fracture mechanics life predictions [3]. With the use of high strength materials at high stresses, the critical crack sizes are very small making accurate predictions of the growth of small cracks essential.

At the notch relevant locations of a gas turbine engine, the plastic strain range would be great enough to consider that low cycle fatigue life is predominately one of fatigue crack growth. In this case, the crack would initiate from some intrinsic or extrinsic flaw in the component which is smaller than the current crack detection limit. The component life could be calculated, then, by integrating the crack growth rate vs. $\Delta \mathrm{K}$ starting at this assumed initial flaw size and ending at the catastrophic size for the component. Lankford and Hudak [4] performed such a calculation for a surface crack growing in a disk web cooling hole. Based on the small crack data for Astroloy of Hicks and Brown [5], their results show that the small crack integration was vastly non-conservative at initial crack depths of $200 \mu \mathrm{m}$ or less when compared to the long crack integration. They also observed that the high cycle fatigue limit of Astroloy is less that $10^{6}$ cycles when based on the small crack integration. This type of low amplitude, high frequency vibration occurs in regions of the disk where the blade attaches. Since a large number of high frequency cycles can accumulate rapidly, the failure of the blade attachment location should happen frequently. The fact that this is not the case suggests that this area of small crack behavior needs further examination.

Though there has been a thorough study of the small crack growth behavior in a number of materials, see reviews on the subject in Refs [6,7], only a limited amount of information exists on the growth of these cracks in nickel-base superalloys. Additionally, only a small fraction of this data was obtained at actual gas turbine engine operating temperatures and related stress-strain conditions. Romanoski and Pelloux [8], for example, have examined crack initiation from intrinsic pores and the subsequent growth of small surface cracks at $649^{\circ} \mathrm{C}$ in the very fine grained $(3 \mu \mathrm{m})$ superalloy IN100 $(\mathrm{pm})$. Their analysis included both the elastic and elastic-plastic crack growth behavior of this material. They did not find accelerated small crack growth response under the conditions investigated. Healy, et. al. [9], on the other hand, found rapid crack growth below the long crack threshold for short cracks at room temperature and $500^{\circ} \mathrm{C}$ in Waspaloy with a grain size of about $40 \mu \mathrm{m}$. This behavior was similar to that found by Hicks and Brown [5] in Astroloy.

The objective of the present study is to investigate the growth characteristics of small 
cracks in the nickel-base superalloy, Alloy 718 , under global elastic-plastic cyclic conditions simulating the cyclic plasticity found at notch locations in gas turbine engines. An emphasis was placed on the detection of anomalous crack growth behavior at short crack lengths and the determination of the mechanism responsible for the behavior. The variables investigated in this study include the strain range, from $0.8 \%$ to $1.0 \%$, and mean strain, from fully reversed to fully tensile cycling.

\section{Experimental Procedure}

The specimens used in this study were machined from a conventionally heat treated rolled ring forging of Alloy 718. This processing resulted in the microstructure shown in Fig. 1 with delta phase along the grain boundaries and twin boundaries and a wide-range grain structure ranging from 20 to $300 \mu \mathrm{m}$ with an average grain size of $130 \mu \mathrm{m}$ (ASTM No. 3). Surface cracks were initiated in rectangular cross section specimens from either hemispherical EDM pits $125 \mu \mathrm{m}$ in diameter or free surface conditions on smooth specimens where initiation occurred at persistent slip bands. Due to the large grain size of this material and the initiation configurations, the minimum crack size in the study was limited to a depth of about $150 \mu \mathrm{m}$. All tests were conducted under total strain control in a laboratory air environment at $650^{\circ} \mathrm{C}$ using a low frequency induction heating system in conjunction with a computer controlled servohydraulic test machine. A triangular wave form was used with a loading frequency of $0.05 \mathrm{~Hz}$ which is below the transition frequency for this material $[10,11]$. The crack growth was measured by a low noise, high gain DC potential drop (PD) system capable of providing continuous measurement of the crack length [12]. To quantify the evolution of the closure in the small cracks, the local crack mouth opening displacement was measured using a laser interferometric displacement gage system (IDG) similar to that developed by Sharpe [13]. The values of crack closure, determined by the method of Chen and Nisitani [14] using the load versus crack mouth opening displacement from the IDG system, were used to determine the effective crack driving force. Figure 2. shows an instrumented specimen with precrack initiated from an EDM flaw. The location of the potential drop wires as well as the microhardness

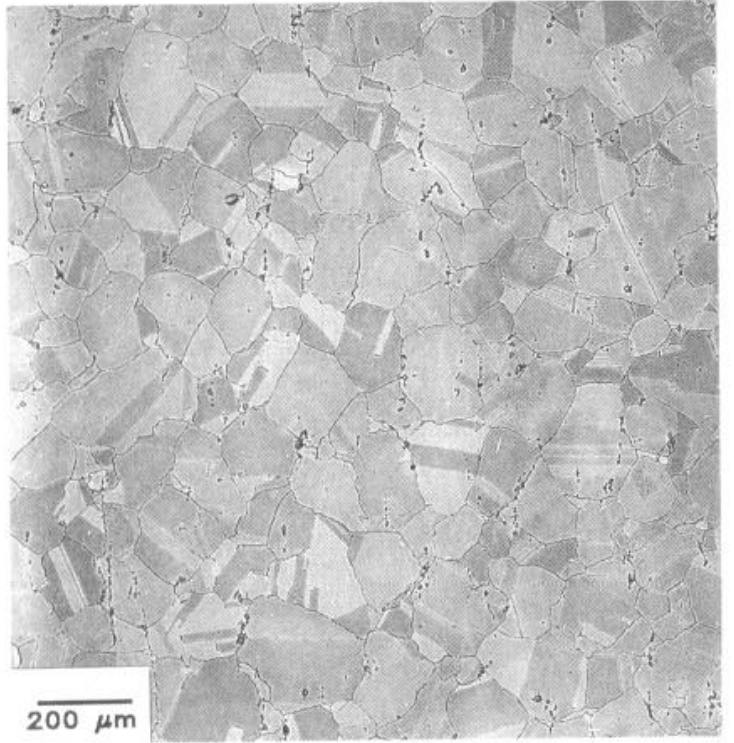

Fig. 1. Microstructure of Alloy 718 .

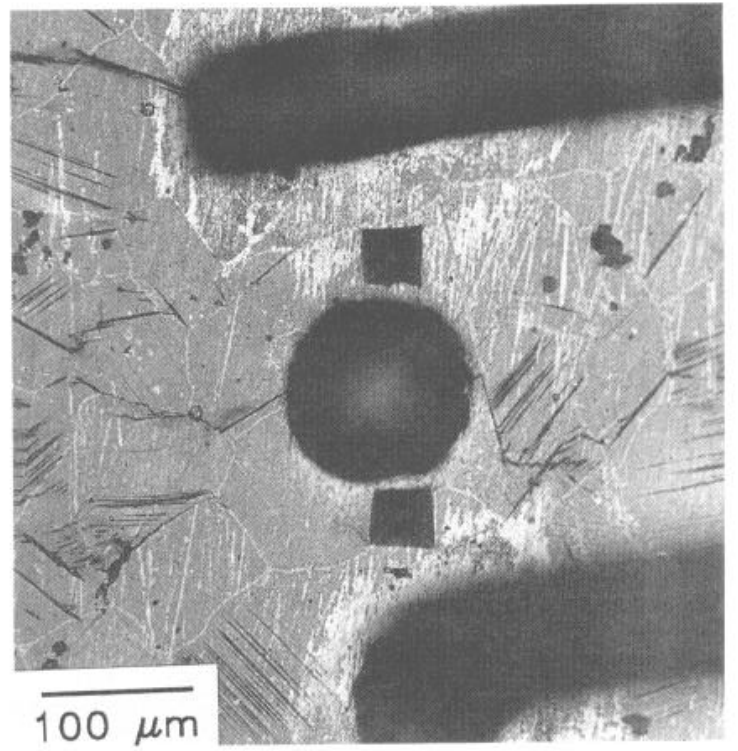

Fig. 2. Detail of an instrumented specimen.

indents used with the laser interferometry system to measure the crack mouth opening displacement are also shown. The crack tip plastic zone size was measured from a post test heat treatment [15] of fractured and sectioned specimens using a particular heat treatment 
procedure that cause the precipitation of stable delta phase nucleating from sheared $\gamma^{\prime \prime}$ precipitates and growing along the active slip plane. By carefully sectioning and polishing of the specimens, the plastic zone can be determined from the extent of the region decorated with precipitates.

\section{Results and Discussion}

Figure 3 shows the fracture surface features associated with the elastic-plastic test conditions. It can be observed that the cracking mode is predominately intergranular in nature. These features are identical to those resulting from the fracture processes of long cracks subjected to the same cyclic loading frequency under linear elastic test parameters [10]. The similarity between these surfaces indicates that the crack growth, in both cases, is driven by the same time-dependent, environment-controlled fracture mechanism [16]. This could imply

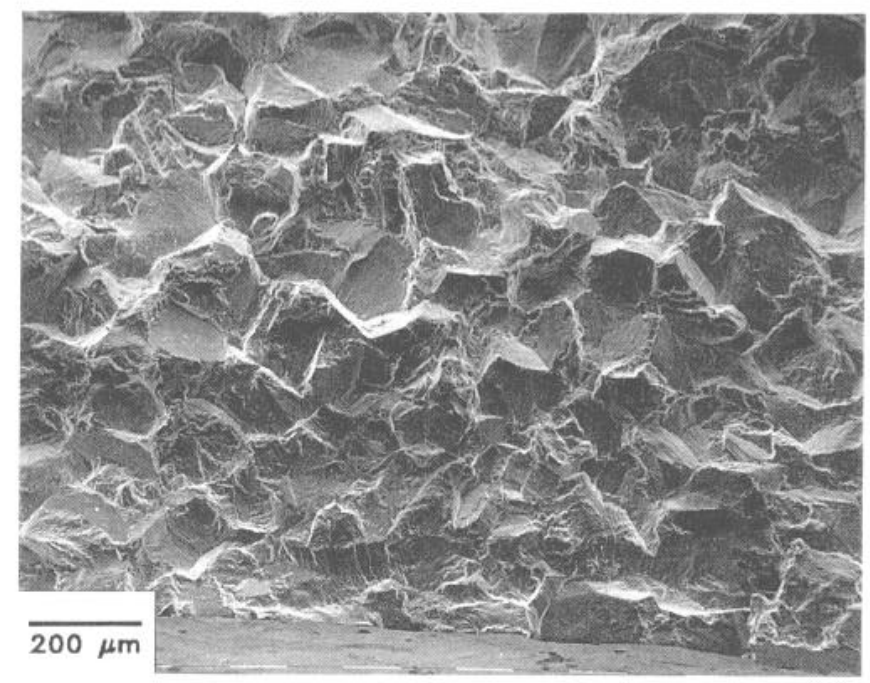

Fig. 3. Typical elastic-plastic small crack fracture surface.

that if the true driving force for the case of elastic-plastic crack growth was found, then a consolidation between the linear elastic and elastic-plastic crack growth rates should exist. The first attempt in this path has been carried out based on linear elastic fracture mechanics with the driving force calculated for surface cracks as,

$$
\Delta K_{p o s}=Y \Delta \sigma \sqrt{\pi a}
$$

where $\Delta \mathrm{K}_{\mathrm{pos}}$ is the stress intensity factor range which takes into account the positive applied load range and $\mathrm{Y}$ is a shape factor chosen as 0.73 which is suitable for the cracks and geometry in the study. The results in the form of da/dN versus $\Delta \mathrm{K}_{\text {pos }}$ are shown in Fig. 4. The validity of using a linear elastic fracture mechanics term is in question for this elastic-plastic study, but the correlation does show some interesting points about the growth behavior. Notice that most of the crack growth rate curves show an initially accelerated region at low values of $\Delta \mathrm{K}$ where the crack length is the shortest. This accelerated region is shown to extend to approximately $450 \mu \mathrm{m}$ in crack depth. Furthermore, the use of $\Delta \mathrm{K}_{\text {pos }}$ did not consolidate the growth rate curves from the different applied strain ranges. This has been attributed to the effect of the global cyclic plasticity as noted by the authors [17]. A more accurate description of the crack growth rates could then be made by expressing the crack growth rates in terms of the 
equivalent stress intensity factor, $\Delta \mathrm{K}_{\mathrm{eq}}$, formulated by Starkey and Skelton [18] as

$$
\Delta K_{e q}=Y\left(\Delta \sigma+E \Delta \varepsilon_{p}\right) \sqrt{\pi a}
$$

where $\mathrm{Y}$ is the LEFM shape factor, $\mathrm{E}$ is elastic modulus, and $\Delta \varepsilon_{\mathrm{p}}$ is the global plastic strain range. The result of this approach, again in the form of $\mathrm{da} / \mathrm{dN}$ versus $\Delta \mathrm{K}_{\mathrm{eq}}$, is shown in Fig. 5. Here the consolidation of the various strain conditions is good and compares well with data from long crack (CT) specimens of the same material. However, the accelerated growth behavior of some of the conditions is still present. This indicates that the global plasticity is

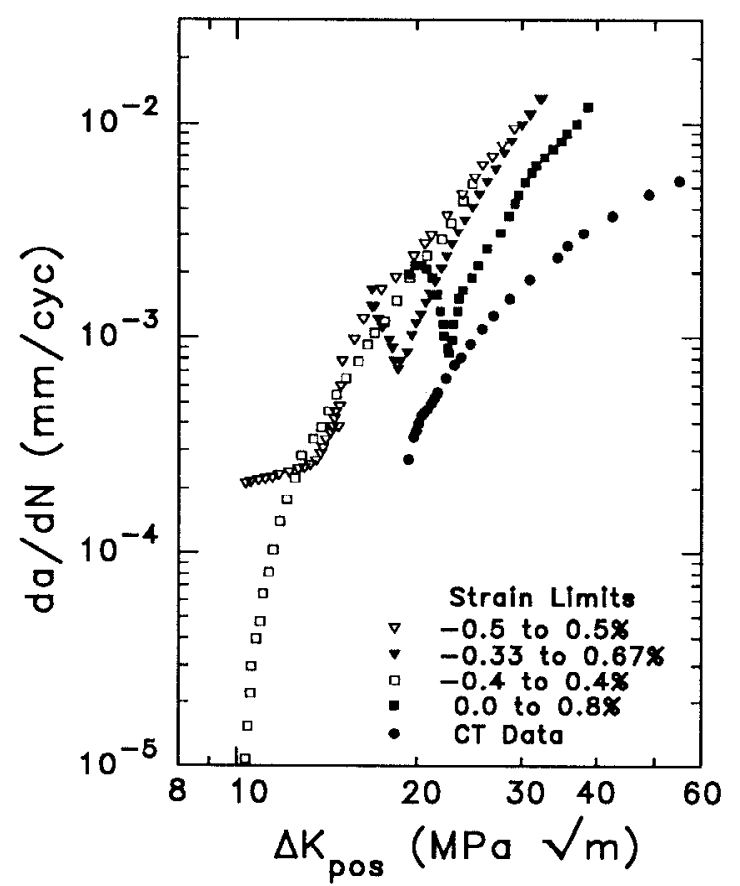

Fig. 4. Crack growth rate versus stress intensity factor $\Delta K_{\text {pos }}$.

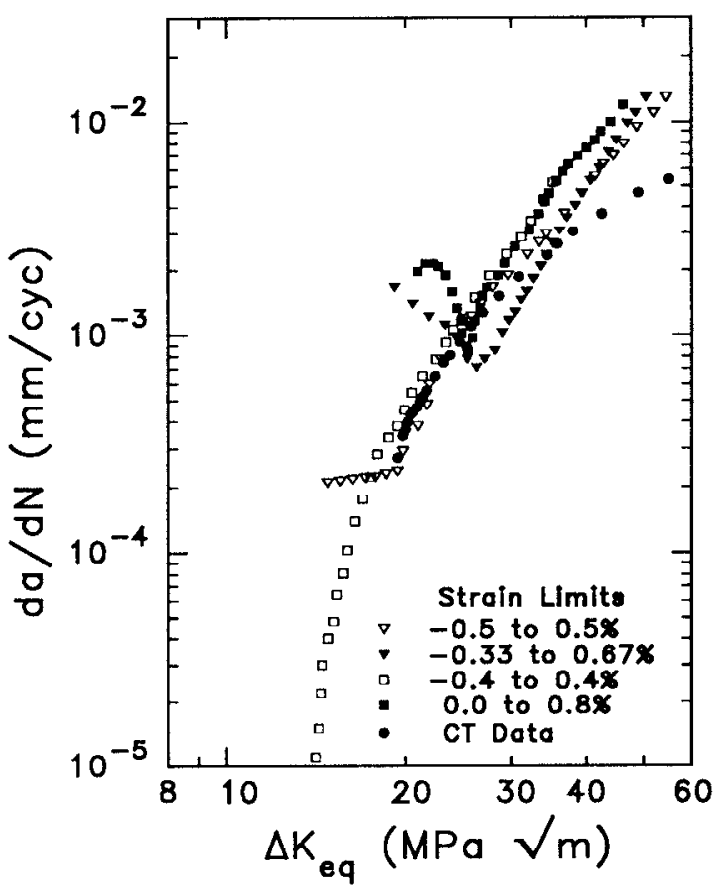

Fig. 5. Crack growth rate versus equivalent stress intensity factor, $\Delta \mathrm{K}_{\mathrm{eq}}$.

important in the overall crack growth behavior of the material but does not control the small crack region.

One of the most common causes of anomalous small crack behavior is the lack of fatigue crack closure [19-20]. Using the measurements of the IDG system, the closure behavior of the cracks is shown in Fig. 6 for several of the conditions tested. Notice that the change of closure is such that at long crack lengths, the closure level tends towards zero load. This trend could be cxplained with the assumption that in these test conditions, closure is controlled by the cyclic strain limits [17]. The crack growth rates could then be compared in terms of the effective stress intensity factor, $\Delta \mathrm{K}_{\mathrm{eff}}$, which is written as

$$
\Delta K_{e f f}=Y \Delta \sigma_{e f f} \sqrt{\pi a}
$$

where $\Delta \sigma_{\text {eff }}=\sigma_{\text {max }}-\sigma_{\text {open }}$. This comparison in the form of $\mathrm{da} / \mathrm{dN}$ versus $\Delta \mathrm{K}_{\text {eff }}$ is plotted in Fig. 7. The consolidation of the data is not improved over $\Delta \mathrm{K}$ and the small crack effects are still pronounced. In a similar fashion, an equivalent effective stress intensity factor, $\Delta \mathrm{K}_{\text {eq eff }}$ can be formulated as 


$$
\Delta K_{\text {eqeff }}=Y\left(\Delta \sigma_{\text {eff }}+E \Delta \varepsilon_{p}\right) \sqrt{\pi a} .
$$

$\mathrm{Da} / \mathrm{dN}$ versus $\Delta \mathrm{K}_{\text {eq eff }}$ is shown in Fig. 8 where it can be seen that, as with $\Delta \mathrm{K}_{\text {eff }}$, the closure did not account for the small crack behavior.

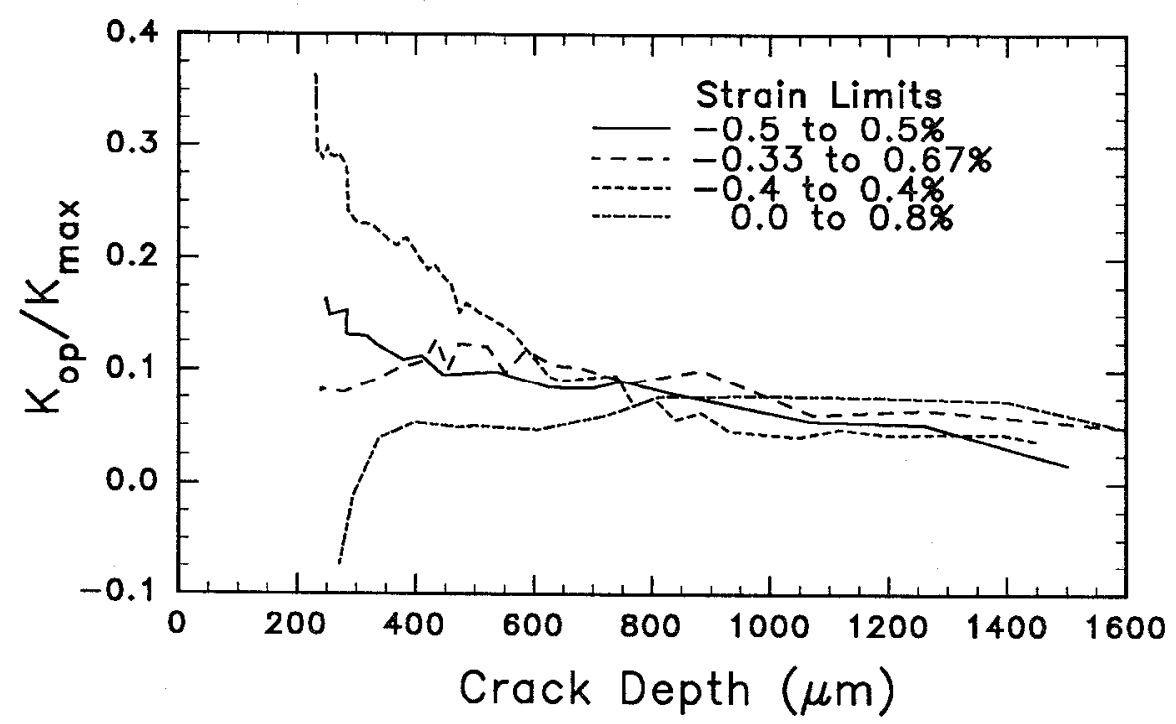

Fig. 6. Crack opening stress as a function of crack length.

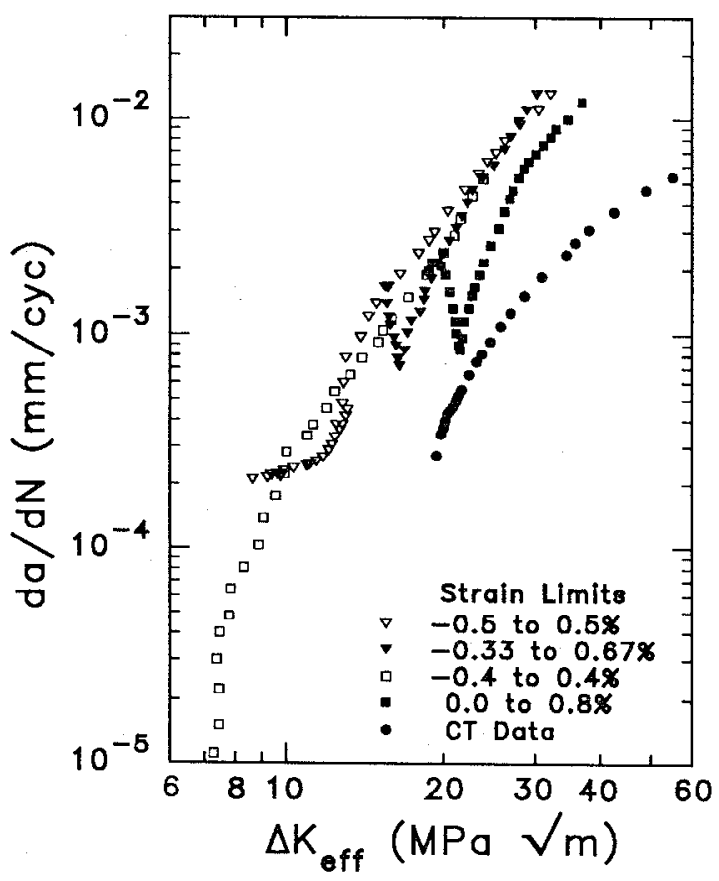

Fig. 7. Crack growth rate versus effective stress intensity factor, $\Delta \mathrm{K}_{\text {eff }}$.

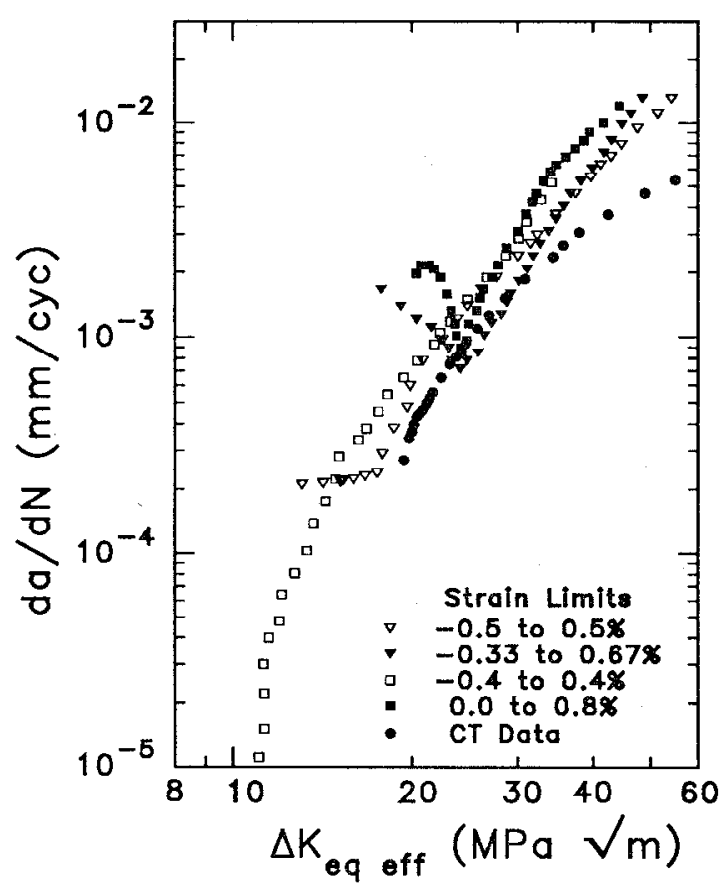

Fig. 8. Crack growth rate versus equivalent effective stress intensity factor, $\Delta \mathrm{K}_{\text {eq eff }}$

The second main cause of anomalous small crack behavior is the possibility of excessive crack tip plasticity which would violate the crack tip zone size calculated on the basis of the 
linear elastic fracture mechanics approach. This was investigated by measuring the crack tip plastic zone size on a number of specimens using the delta treatment technique as previously described. A photomicrograph is shown in Fig. 9, of a delta treated specimen. The crack tip plastic zone is clearly marked by the precipitation of delta phase and is distinct from the substantially lower level of plasticity in the bulk of the material. Using a SEM, the plastic zones were measured at the crack surface, and at $30^{\circ}, 60^{\circ}$, and $90^{\circ}$ from the surface on

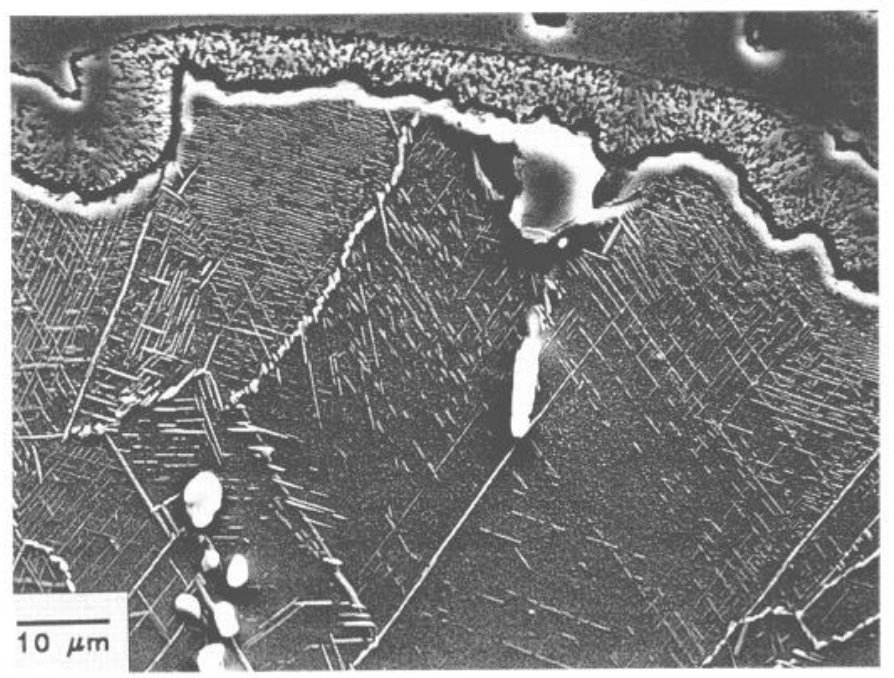

Fig. 9. Decoration of the crack tip plastic zone by the delta treatment technique.

specimens that were sectioned radially, relative to the crack center, and polished. This showed the range of plasticity from plane stress at the surface to plane strain at the $90^{\circ}$ slice. Results of these measurements for a $0.0 \%$ to $0.8 \%$ total strain range test, which did show accelerated growth in the small crack region, are shown in Fig. 10. Here, it is seen that the plastic zone size is linear with respect to $\mathrm{K}_{\text {max }}^{2}$ even at small crack lengths, less that $500 \mu \mathrm{m}$, where the anomalous growth rate is observed and that the plane stress to plane strain plastic zone sizes differ by a factor of approximately three which is predicted by the Irwin plastic zone size

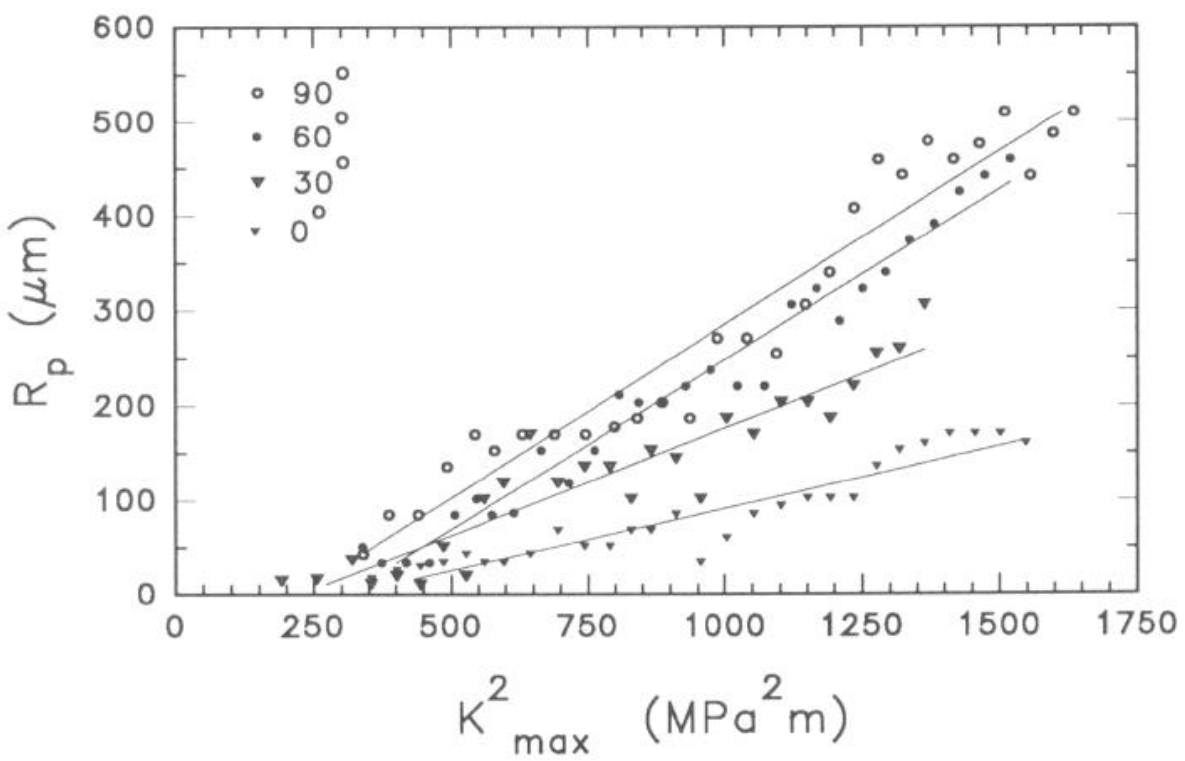

Fig. 10. Crack tip plastic zone as a function of crack length. 
calculation. All of the specimens examined in this manner followed the same trend as the specimen detailed above which indicates that the anomalous small crack growth is not accompanied by excessive plasticity which would contradict the small scale yielding assumption.

On the basis of the above discussion, it is concluded that the acceleration phenomena associated with small crack growth behavior can not be entirely described in terms of crack tip closure or excessive crack tip plasticity. One of the factors that, however, was not considered here is the observation that the accelerated growth of small cracks in this study was only present in conditions where high temperature crack growth followed a room temperature precracking. If the yield value of the crack tip material undergoes a high to low variation during the transition from room to high temperature cracking, this variation may then be sufficient to cause crack tip transients of a form similar to that observed in underload applications. To examine this possibility, two tests were conducted in which the cracks were initiated at high temperatures under elastic-plastic total strain control, thereby eliminating a transient precrack effect. The high temperature initiation was carefully performed to produce similar initial crack lengths to the room temperature precracked specimens. To do this, the specimens were cycled at the test conditions for a number of cycles estimated to initiate a crack. The specimens were then brought to zero load and cooled to room temperature after which plastic replicas were taken of the specimen surface to detect cracks. When a crack was found of sufficient size and oriented on the specimen similar to those grown from the EDM flaws, the specimen was instrumented for the IDG and PD measurements and the test was continued. In restarting the tests, care was taken to return the specimen to the appropriate location on the stress-strain hysteresis loop. The results of one of the high temperature initiation tests is shown in Fig. 11 in terms of $\Delta \mathrm{K}_{\text {eq eff }}$ with the data from a room temperature initiated crack under the same global stress-strain conditions, $-0.33 \%$ to $0.67 \%$ strain range. Notice that the initial accelerated crack growth rate region is missing in this specimen.

To confirm that the anomalous behavior is associated with the transient caused by the precrack technique and not the crack length, a test was run on a specimen with a longer initial crack length of $490 \mu \mathrm{m}$ which is longer than the duration of the transient growth behavior for a smaller crack. Fig. 12 shows the crack growth rates for two cracks cycled under the same cyclic conditions, $0.0 \%$ to $0.8 \%$ strain range, with different initial crack lengths. It can be seen that the long crack shows a similar initial acceleration in growth rate even for a crack length over twice that of the shorter crack. This indicates that the anomalous crack growth is not related to a small crack length and does not represent an intrinsic material property. A more detailed discussion of this effect can be found in ref [21]. The accelerated growth rates seen here are similar to initial crack growth transients seen in the titanium alloy Ti-1100 tested in high vacuum at $593^{\circ} \mathrm{C}[22]$. The specimen in this case was a compact tension type and the initial crack length is over $8 \mathrm{~mm}$ (the specimen width was $20 \mathrm{~mm}$ ). One explanation for this observation was the increased slip reversibility in vacuum due to the lack of oxide pinning of the slip planes which would cause a enlargement of the crack tip plastic zone with the vacuum cycling.

It is assumed that in service, the crack initiation process will be similar to a laboratory high temperature initiation condition where no true small crack behavior exists in this material. In this case, residual life prediction techniques, such as that by Lankford and Hudak [4], can be accurately made using long crack growth data. For cracks growing in the elastic-plastic fields of notch roots it is necessary to account for the cyclic plasticity in the notch root using a driving force term such as $\Delta \mathrm{K}_{\mathrm{eq}}$ or $\Delta \mathrm{J}$. Also, the lower limit of crack size should be chosen based on a physically sound initiation process. In this material, where cracks are generally observed to initiate along persistent slip bands, the minimum crack length that is required to preform a life prediction integration could be obtained in relation to the grain size dimensions. 


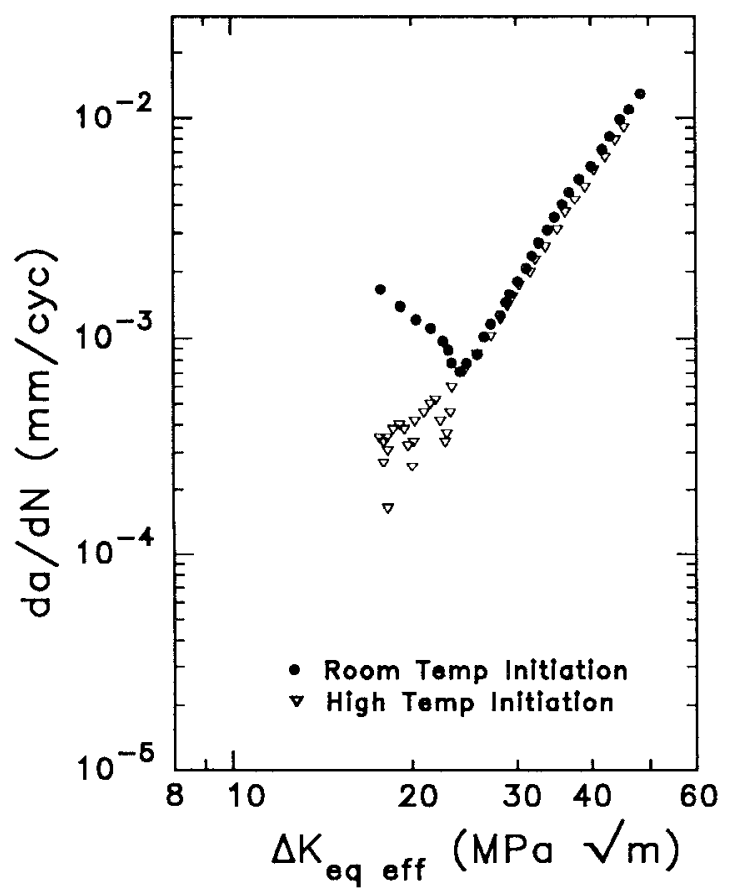

Fig. 11. Crack growth rate versus equivalent effective stress intensity factor, $\Delta \mathrm{K}_{\text {eq eff }}$, for room and high temperature initiated cracks.

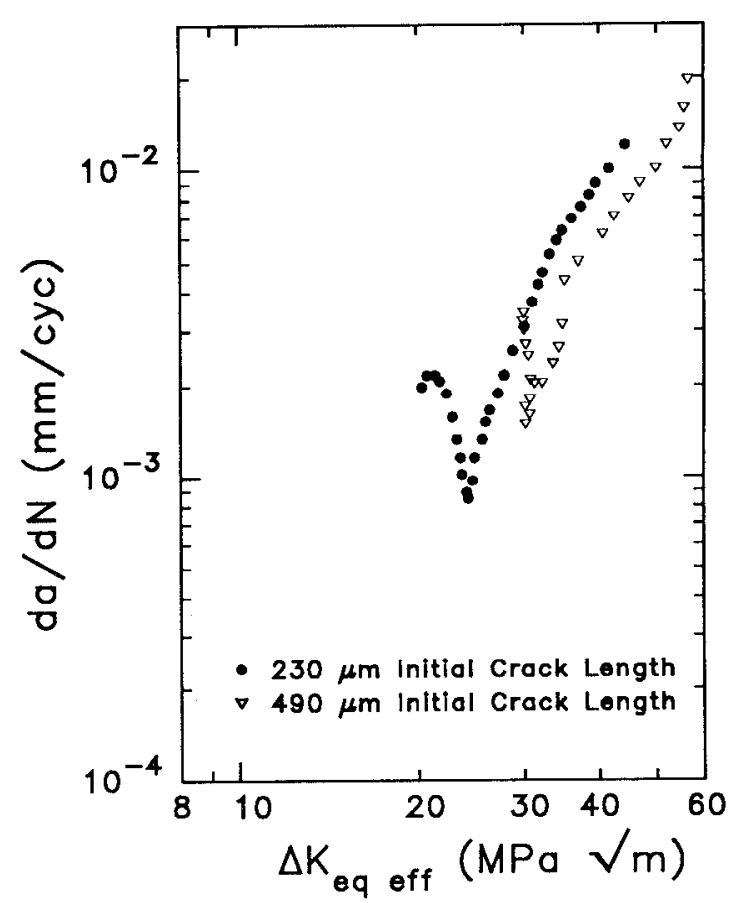

Fig. 12. Crack growth rate versus equivalent effective stress intensity factor, $\Delta \mathrm{K}_{\text {eq eff }}$, for cracks with initial lengths of $230 \mu \mathrm{m} \&$ $490 \mu \mathrm{m}$ (precracked at room temperature).

\section{Conclusions}

In Alloy 718 under elastic-plastic cyclic conditions, the anomalous small crack growth rates are not an intrinsic feature of the material and are transient effects due to the experimental precrack technique and are not crack length dependent.

The growth of cracks under elastic-plastic conditions is consolidated with linear elastic long crack data using the term $\Delta \mathrm{K}_{\mathrm{eq} \text { eff }}$ by accounting for the global plasticity and the level of crack closure.

In turbo-machinery, therefore, accurate residual life predictions for components made from Alloy 718 can be based on the integration of long crack growth rate data of this alloy. This requires, however, that the lower limit of crack length is chosen based on a physically interpreted crack initiation process.

\section{Acknowledgements}

This study was supported by United Technologies, Pratt \& Whitney Aircraft Group. Mr. J. Hill was the program monitor.

\section{References}

1 J.M. Larsen, and T. Nicholas, "Cumulative-Damage modeling of fatiguc crack growth in turbine engine materials", Eng. Frac. Mech., 22 (4) (1985), 713-730.

2 Military Standard, "Engine Structural Integrity Program (ENSIP)" (MIL-STD-1783,USAF, 1984).

3 M.A. Hicks, and A.C. Pickard, "Life Prediction in Turbine Engines and the Role of Small Cracks", Mat. Sci. and Eng., Al03 (1988), 43-48.

4 J. Lankford, and S.J. Hudak, Jr., "Relevance of the Small Crack Problem to Lifetime Prediction in Gas Turbines", Int. J. of Fat., 9 (2) (1987), 87-93. 
M.A. Hicks, and C.W. Brown, "A Comparison of Short Fatigue Crack Behavior in Engineering Alloys", Fatigue '84, ed. C.J. Beevers, EMAS Ltd., UK, (1984), 1377-1343.

6 K.J. Miller, "The Behavior of Short Fatigue Cracks and Their Initiation Part I- Review of Two Recent Books", Fat. Frac. Eng. Mat. Struc., 10 (2) (1987), 75-92.

7 K.J. Miller, "The Behavior of Short Fatigue Cracks and Their Initiation Part II- A General Summary", Fat. Frac. Eng. Mat. Struc., 10 (2) (1987), 93-113.

8 G.R. Romanoski, Jr., and R.M. Pelloux, "The Fatigue Behavior of Small Cracks in an Aircraft Turbine Disk Alloy", Elevated Temperature Crack Growth, eds. S. Mall and T. Nicholas, ASME, (1990), 7-23.

9 J.C. Healy, L. Grabowski, and C.J. Beevers, "Short-Fatigue-Crack Growth in a Nickel-Base Superalloy at Room and Elevated Temperature", Int. J. of Fat. 13 (2) (1991), 133-138.

10 H. Ghonem, D. Zheng, E. Andrieu, and A. Pineau, "Experimental Observations and Quantitative Modelling of Oxidation-Assisted Crack Growth Bchavior in Alloy 718 at $650^{\circ} \mathrm{C}$, ( $\Lambda$ nnual Report AFOSR-89-0285, Bolling AFB, Washington, DC, 1990).

11 T. Nicholas, T. Weerasooriya, and N.E. Ashbaugh, "A Model for Creep/Fatigue Interaction in Alloy 718", Fracture Mechanics: 16th Symp., ASTM STP 868, eds. M.F. Kannien, and A.T. Hopper, (1985), 167-180.

12 A.H. Rosenberger, and H. Ghonem, "The Effect of the Compressive Stress-Strain Excursion on the Elastic-Plastic Small Crack Growth in Alloy 718 at $650^{\circ} \mathrm{C}$, proceedings of Third International Conference on Low Cycle Fatigue and Elasto-Plastic Behavior of Materials, Sept., 1992, Berlin.

13 W.N. Sharpe, Jr., "Interferometric Surface Strain Measurement", Int. J. Nondest. Testing, 3 (1971), 59-76.

14 Chen, D.-H. and Nisitani, H. "Analytical and Experimental Study of Crack Closure Behavior Based on an S-Shaped Unloading Curve", Mechanics of Fatigue Crack Closure, ASTM STP 982, eds. J.C. Newman, Jr., and W. Elber, ASTM,(1988), 475-488.

15 M. Clavel, D. Fournier, and A. Pineau, "Plastic Zone Sizes in Fatigue Specimens of INCO 718", Metallurgical Transactions A, 6 (1975), 2305-2307.

H. Ghonem, and D. Zheng, "Depth of Intergranular Oxygen Diffusion During Environment-Dependent Fatigue Crack Growth in Alloy 718", Mat. Sci. and Eng. (A150) (1992), 151-160.

17 A.H. Rosenberger, and H. Ghonem, "Effect of Cycle Mean Strain on Small Crack Growth in Alloy 718 at Elevated Temperatures", Fat. Frac. Eng. Mat. Struc., to be appear, (1992).

18 M.S. Starkey, and R.P. Skelton, "A Comparison of the Strain Intensity and Cyclic J Approaches to Crack Growth", Fat. Eng. Mat. Struc., 5 (4) (1982), 329-341.

19 P.K. Liaw, and W.A. Logsdon, "Crack Closure: An Explanation for Small Fatigue Crack Growth Behavior", Eng. Frac. Mech., 22 (1) (1985), 115-121.

20 J.M. Larsen, J.C. Williams, and A.W. Thompson, "Crack-Closure Effects on the Growth of Small Surface Cracks in Titanium-Aluminum Alloys", Mechanics of Fatigue Crack Closure, ASTM STP 982, eds. J.C. Newman, Jr., and W. Elber, ASTM, (1988), 149-167.

21 H. Ghonem, and A.H. Rosenberger, "Small Crack Growth Phenomena in Alloy 718", Fat. Frac. Eng. Mat. Struc., to be published.

22 R. Foerch, A. Madsen, and H. Ghonem, "Environmental Influcnce on the Fatigue Crack Growth Performance of Ti-1100 at Elevated Temperatures", Seventh World Conference on Titanium, San Diego, CA, (1992). 